The Journal of Public Space

ISSN 2206-9658

2018 | Vol. 3 n. 3

https://www.journalpublicspace.org

VIEWPOINT

\title{
Art as a catalyst to activate public space: the experience of 'Triumphs and Laments' in Rome
}

Thomas Rankin

California Polytechnic Rome Program, Italy trankin@calpoly.edu

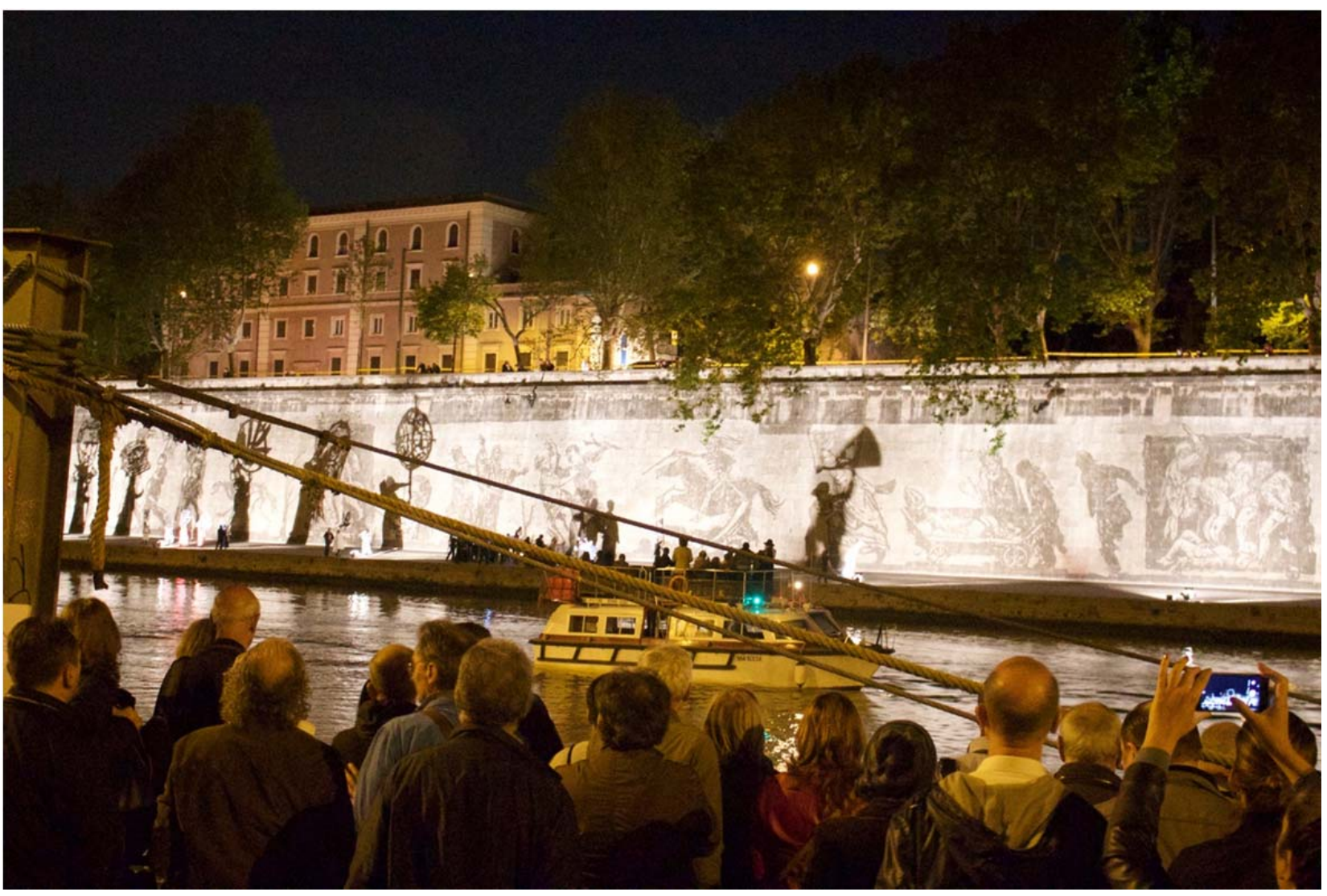

Figure I. 'Triumphs and Laments' art work by William Kentridge in Rome, on the Tiber riverfront. Source: the author.

Many cities have rediscovered and reinvented their river fronts as public spaces in recent years. From New York to Seoul, urban waterways which were forgotten, marginalized, or outright abandoned are now filled with life. In each case the transformation was spurred by a combination of grass roots, bottom-up initiative and savvy government recognition of 
the projects' potentials. Once the city leaders embraced the projects - and not a moment sooner - public and private funding materialized and bureaucratic barriers disappeared. In Rome, whether due to the complexity of the chain of responsibility for the river front, or simply an ingrained aversion to progressive planning - saying no or saying nothing is much easier than taking responsibility for positive change - initiatives to renew the urban riverfront have been small and disconnected. Diverse interests ranging from green space to water transit, from river front commerce to ecological restoration, have all vied for a role in the river's regeneration.

But one particular discipline, that of art, has succeeded more than others in attracting international attention and changing the way people in Rome and throughout the (art) world see the Tiber. Artist William Kentridge, with his project 'Triumphs and Laments', using the simple technique of selective cleaning of the Tiber embankment walls, revealed to the world a procession of figures which populate the riverfront with a life that it hasn't seen in centuries.

How does this experience, spearheaded by a grassroots organization with ties to both the local architectural community and the international art world, provide a model for public space regeneration? Using the Kentridge project as a case study, how we can better understand how art can serve as a catalyst to spur social change, and how can the city leverage its existing resources to do more with less?

Before examining the phenomenon of 'Triumphs and Laments', it is worth remembering that the collective memory of Rome has repeatedly been shaped by top-down plans for urban form, imposed onto sites cleared by fires and floods, or in its disabitato, tracts of green space abandoned by a shrinking population. Nero rebuilt after the fire of 64 AD with wider, straighter streets, and the Renaissance popes from Julius II to Sixtus V cut axial boulevards through the historic fabric to establish new urban connections. In the 20th century Mussolini's sventramenti scarred the city while gouging out historic fabric and replacing it with over-scaled monumental architecture. And already decades before Fascism, after becoming capital of unified Italy, Roma Capitale saw the radical transformation of its most central historic infrastructure, the Tiber river. In today's global urbanization, city-making often means inserting new pieces of architecture, or even complete pieces of city, what Fumihiko Maki called 'collective form' especially in urban areas where large tracts are abandoned or devastated by disasters. Even in the Eternal City there is a role for big thinking, for regional strategies, and for projects which address infrastructure as a catalyst for urban regeneration.

But such bold moves are not the only way to shape cities. Equally frequently change comes from unforeseen sources. The choice of location of the Italian film director Paolo Pasolini for the film 'Accattone' was instrumental in cultivating a new collective identity for Rome's Pigneto neighborhood, as recent street art has revolutionized Ostiense. Such phenomena resemble the effect of mutagens on natural growth; a small deviation is often enough to change the course of evolution. Sometimes - and this is true especially in cities like Rome where architecture has had centuries to accrue - urban architects can leverage the existing fabric and artifacts and produce successful urbanism with the most minimal of interventions. Top-down initiatives very often result in over-determination of public space, resulting in what Richard Sennett calls the 'Brittle City' and which Jane Jacobs contrasted with the notion of 'Open City', one where juxtaposition of different and potentially contrasting uses and users enliven public space. 
Jacobs' vision of vibrant urban space calls to mind the piazzas of Rome that her generation, especially architects like Robert Venturi and Denise Scott Brown, travelled to Italy to study. Today these historic spaces are more frequently focused on commerce and consumption and fall into the trap of crass tourism. While public spaces on the edge of town often boast more authenticity, a diversity of use and user, they lack the monuments that draw people and create identity. Nevertheless, in recent decades designers have been drawn to the periferia by this very quality of cultural marginalization. The historic centers have been left as lost causes sacrificed to mass tourism. Somewhere between the center and the city fringes lies the Tiber, neither geographically peripheral nor experientially central, an ambiguous terrain vague running through the heart of Rome. The Tiber Riverfront has not always been the desolate wasteland that presents itself to us today. In 1704 Alessandro Specchi completed the Porto di Ripetta, a bustling baroque scalinata descending from the city to its river banks, and inversely welcoming merchants and visitors arriving by boat up into the Campus Martius. Images of the Tiber from this time show lively boat traffic, floating mills, and great numbers of people lounging around the river banks. Fishing and swimming were so popular that they were regulated by papal decree. As Rome's most important economic, environmental, ecological, and recreational resource, according to architect and Tiber historian, Maria Margarita Segarra Lagunes, the Tiber didn't just run through the city; it was part of the city.

But the Tiber was both a blessing and a curse. The lifeblood of the city could also prove a menace when heavy rains upstream filled its narrow channels causing it to breach its banks. On 28 December 1870, just months after Italian nationalists breach the Aurelian Walls (establishing Rome as the nation's new capital), the Tiber river breached its banks and flooded the city to a level not seen since 1637. The nascent nation's capital was mortified by the embarrassing inaugural performance, and flood-prevention measures, which had been discussed and debated since the late Republic, became urgent. Smart solutions such as bypass canals to mitigate extreme water levels were set aside in favor of the most destructive option: demolition of the fabric along the river and construction of the tall embankments walls, the muraglioni, which we see today.

Between 1880 and 1900 vast tracts of land on both sides of the Tiber were commandeered and cleared. The narrow streets of the former Jewish ghetto and the dense wall of buildings, which had stood directly along the river, forming an occupied architectural edge, were all razed to be replaced by speculative modern structures. In fact, the creation of the Tiber embankment served both infrastructure and urban renewal, in the worst sense of the word, not unlike the cleansing efforts which would mar American cities and infuriate Jane Jacobs in the middle of the following century. Rising forty feet from the lower riverside paths, these travertine walls effectively severed the city from its river. In her 2009 essay entitled 'Rome's Uncertain Tiberscape', Kay Bea Jones describes how

"with street life, bridge crossing, and public activities now thriving fifteen meters above the Tiber's water level, which rises and falls with little effect, the relationship of modern Romans to their river was detached and would be changed forever." (Jones, 2009)

Since the completion of the embankment walls, Rome's riverfront has stood as a piece of obsolete and abandoned infrastructure, marginalized like the distant periphery despite its location in the heart of Rome. 
For many Romans and foreign romaphiles alike this neglect is unacceptable. Since the 1960s architectural proposals have addressed the role of the river, often with fantastic structural gestures (c.f. Franco Purini and Laura Termes' project for a new Tiber bridge, or James Stirling's Tiber-spanning entry in the 'Roma Interotta' exhibit) and the river continues to draw the attention of urban and landscape designers.

As a design instructor for various American architecture schools I have frequently used the riverfront as our laboratory. But it was in 2013 when I accepted the Tevereterno Onlus Board's invitation to serve as Director that I began to realize the challenges of carrying out real projects on the river.

Tevereterno was the creation of New York artist Kristin Jones who had come to Rome in the 1980s with a Fulbright, and later returned as a Fellow at the American Academy. At the Academy her project was focused on the potential of the Tiber riverfront as a site for artistic programming. Not the whole riverfront, but a particular section, between Ponte Sisto and Ponte Mazzini, which she dubbed 'Piazza Tevere', where the embankment walls run parallel to one another for a half a kilometer, cut perpendicularly by the two bridges to form a perfectly rectangular space. In order to turn the vision of Piazza Tevere into reality, an organization was needed. In 2004 Jones called on friends, old and new, in Rome's cultural community - Architects Carlo Gasparrini, Rosario Pavia and Luca Zevi and, together, three Italian architects and one American artist, they formed the 'Associazione Tevereterno Onlus'.

Over the course of a decade Tevereterno promoted a series of cultural events on the site but it wasn't until the arrival of William Kentridge that the project took on a scale proportional to the river's role in the city and the city's role in Western culture.

The South African virtuoso is one of the most world's important living artists. Romans who attended his production of Refuse the Hour at the Teatro Argentina in Rome, in late 2012 , were entranced by his rich interweaving of sound, text, image, of science, history, literature, and personal anecdote. At the same time Rome's MAXXI museum - the National Museum XXl's Century Arts - was showing Kentridge's installation entitled 'The Refusal of Time', built around the same themes from the work of Peter Galison, a Harvard-based historian of science.

In November 2012, while Kentridge was in Rome for 'Refuse the Hour', Tevereterno set up a test projection of images and video onto the embankment walls in order to show the artist the possibilities. He watched from above, and then descended to the riverbanks below, observing the scale of the images (his own drawings from the recent performance).

After the last performance of 'Refuse the Hour' there was a party in the spacious, artfilled home of a mutual friend off of Piazza Venezia. All eyes were on William Kentridge when, after years of discussions, he announced his decision to embark on his first ever experience in free public art, here, on Piazza Tevere. "If not now, when?" he announced. It was as if the floodgates had opened and the creative forces rushed on through. The proposed medium, selective cleaning of the river walls, had been tested and approved, but the exact subject had not yet been identified. Kentridge wasn't going to start drawing without assurance that permits and funding would be in place to make the project a reality, but ideas started to take form. He was interested in iconography from Rome's long and ongoing history, specifically images recognizable as victory or defeat, triumphs or

\footnotetext{
'Associazione Tevereterno Onlus' - https://www.tevereterno.it/
} 
laments. Under the direction of art historian Lila Yawn, professor at the nearby John Cabot University, a team was organized to collect images for Kentridge to draw from, and eventually a selection which he would draw in his studio. Two databases (one for triumphs and one for laments) were quickly merged into one when it became clear that every victory represented another's defeat, for every triumphal celebration someone else was mourning their losses.

Kentridge is remarkably humble for an artist of his stature. He listened with childlike fascination to explanations of images, to stories from Rome's history. He learned, he made connections, but as a visual artist, not a historian, he gravitated to the images themselves independent of the story they told. An emaciated horse from the base of Trajan's column, the Renault 4 with its hatch swung open to reveal the body of Aldo Moro (the chairman of the Italian Christian Democratic party and former Italian Prime Minister, who was killed by Red Brigades in 1978), the war-worn prisoners carrying their treasures from the Arch of Titus, all were chosen for the emotions evoked, not for the specific message conveyed.

Parallel to the first iconographic research, another process was underway, the quest for signatures. Tevereterno Vice-President Valeria Sassanelli and I sent around documents, scheduled appointments, rescheduled appointments, met with officials, and patiently and persistently pushed to obtain the necessary permits. At each pass I filed away contact information in our growing database and added nodes to a map I called 'Tiber Bureaucracy'. So many stakeholders played a role in Rome's river. Some thirteen were directly responsible, from the Lazio Region to Roma Capital down to the Primo Municipio, AMA (Rome's company in charge of waste collection), ACEA (Italian energy and water supply company) and the Polizia Fluviale, but many others had an indirect interest in the river's health: international cultural institutes, embassies, environmental organizations, sporting clubs, and many, many others. The map became a sort of octopus. And the process became what Kentridge would describe as an operatic drama:

"One could do an interesting timeline of refusals and newspaper articles and phone calls [...] waiting for this politician to be thrown out or to resign and for a new one to come in" (Kentridge, 2016).

We met with authorities on all levels. Many, like Rome's Mayor at the time, pledged their support informally but when asked to write a letter to that affect were less forthcoming. Our support went far beyond national boundaries: at one point I brought U.S. Ambassador John Phillips and his wife Linda Douglass to Piazza Tevere where they participated in our annual 'Tevere Pulito' clean-up and began spreading the word about the plans to revitalize Rome's Riverfront at high levels. The network of supporters mushroomed.

But at the same time there was a mixed reaction in the press, beginning with a headline in Rome's daily newspaper 'Il Messaggero' which included the word 'graffiti'. The mistaken idea that a foreign artist would be invited to scrawl his graffiti on the walls of Rome's monuments (not at all what the project entailed) obviously aroused the rage of many Romans and it took a huge public relations effort on our part to explain that as an organization we were cleaning up the site, and the artistic medium was actually cleaning the walls. But the press, especially the art journal 'Artribune', began to see the importance of the work and positive articles appeared worldwide. 
In June 2014 Tevereterno organized an event at the MAXXI Museum, an artists' workshop culminating in a projection and performance. Rome's art world was present in numbers, as were journalists, but with few exceptions the event was boycotted by all levels of public administration. Each time I spoke with Mayor Ignazio Marino, he said he supported the project, but he never made a proactive effort to bring it to fruition. When a meeting between Marino and Kentridge finally took place, it was a fortuitous one, the artist on a boat, filming footage for a future documentary, the Mayor on his bike along the riverside path.

By mid 2015 the arduous permitting process was achieving its desired results and Kentridge began drawing without reserve. Now that 'Triumphs and Laments' was moving forward, it became urgent to raise the required funds, but management of the project was problematic. Artistic Director Kristin Jones, who was to report to me as Tevereterno Director in order to coordinate fundraising efforts, continued to act autonomously as she had always done. Kentridge's studio chose a professional outside producer with whom they had worked in the past. The project soon had three competing fundraising efforts running in parallel, only one of which brought funds to the organization that had launched the project years earlier and was working full-time to make it happen. As the deadline came closer, the strategic plan which the Tevereterno board had approved was boldly and bombastically disregarded, like the traffic laws on Rome's streets. The whole communications and outreach plan came to a standstill just months from the anticipated initiation date of the selective cleaning work.

If it weren't for Kentridge's galleries taking on the responsibility for paying for the cleaning and the inaugural events, the project would have failed at this point. There was simply not enough money. Some compensation was also paid to certain Tevereterno board members but not to the administrative staff nor the development team who continued to work for free. However, the project was too exciting to be sidetracked by financial limitations.

Despite these obstacles, 'Triumphs and Laments' moved forward to completion. Gianfranco Lucchini oversaw the technical production, specifically the transformation of the digital drawings emerging from Kentridge's studio into polycarbonate stencils. Starting in early March 2016, these were suspended against the embankment walls while workers in cherry pickers sprayed water against the stone surface, cleaning away the dirt. As the first stencils were removed, the figure of Mussolini on a horse emerged, his raised hand severed and floating ominously in a Roman salute just above the horse's tail, the whole thing riddled with what looked like shrapnel. Then Pasolini's body, Remus, the head of Cicero, and Minerva. The cleaning started in the middle and worked outwards until early April when all eighty or ninety figures (depending on how one counts them) were visible. Soon preparations would be underway for the inaugural events, the most ambitious theatrical spectacle William Kentridge had envisioned to date. 

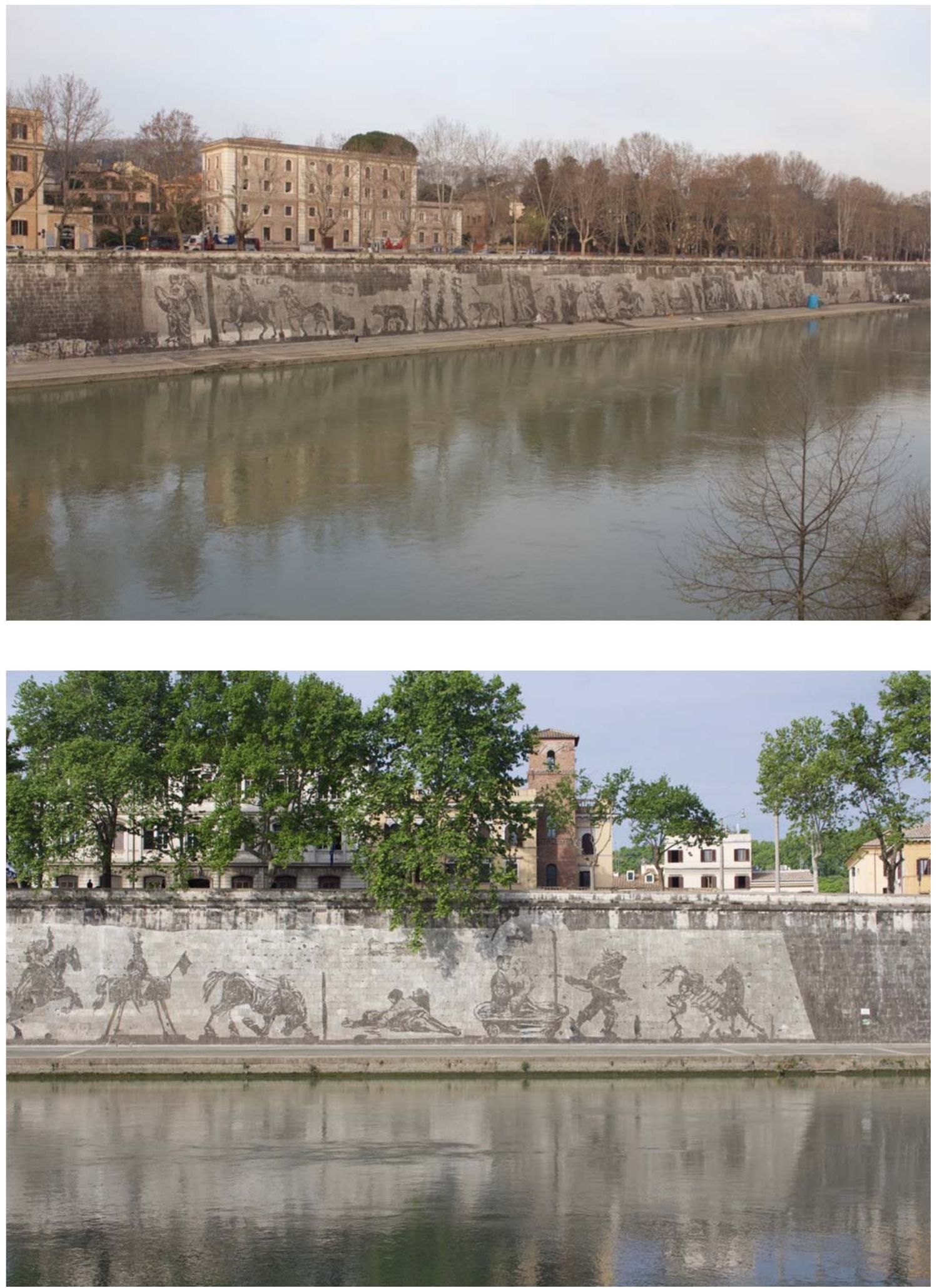

Figure 2 and 3. 'Triumphs and Laments' art work by William Kentridge in Rome, on the Tiber riverfront. Source: the author. 
From the moment the 500-meter long frieze was completed it began to decay back into nature. This is inherent in the ephemeral nature of the technique, and one of the reasons there was a sense of urgency to shine the spotlight on the work while it was fresh. Ironically the same authorities who had voiced opposition to the project early on, and who we had attempted to assuage with assurances that it was just a temporary work, now bemoaned the figure's impermanence. Once they realized that Rome had its own William Kentridge piece, they wanted it to be eternal, but Kentridge refused any suggestions of conserving it artificially. Rome, we pointed out, has a long tradition of ephemeral phenomena, from triumphal processions to Baroque processions to the 'Estate Romana' festivals under cultural commissioner Renato Nicolini (1977-1985). The ephemeral actually leaves a more lasting impression on the viewer, Claudio Strinati pointed out, because the memories are left unadulterated by later transformations. What is certain is that anyone present at the performances of 'Triumphs and Laments' on Piazza Tevere, on 21-22 April 2016, will remember the experience for the rest of their lives. That night, on a boat in the middle of the Tiber with good friends, in the company of William Kentridge who was also watching for the first time the unfolding of this performance, I felt that it had all been worth it. Thousands of people who thronged the river's left bank and bridges to watch and experience the spectacle. It was evident that our mission, to reactivate the Tiber riverfront with site-specific art, had been achieved. The world had rediscovered Rome's river, and now things would change. It would be nice if the story ended here, with the anticipation of improvements, of the physical transformation of the riverfront to make it more amenable to visitors, now that city officials had been shown what an important resource they had. An article in the New York Times by Elisabetta Povoledo $(2016)^{2}$, right after the inauguration, focused on the grassroots volunteer efforts of Tevereterno and others which indicated a change of current for Rome's river. It was clear that the next step would be to improve access, seating, lighting, to improve upgrade maintenance, in short to render Piazza Tevere a more presentable civic space on the international stage. Days before the inauguration, Tevereterno had been busy with almost a hundred volunteers cleaning the site, urging officials to find a reasonable solution for the homeless under the bridge. With the huge success of the event, I had no doubt that the playing field had changed.

But even so, Piazza Tevere fell back into a state of abandon. The homeless living under Ponte Mazzini returned, the weeds began to grow back, the stench, broken bottles and syringes again filled the stairs. In early July a young American student enrolled in a study abroad program at John Cabot University was found dead in the Tiber. The last people to see him alive were the denizens of Ponte Mazzini with whom he had been seen having an altercation, the same people who apparently still occupy the public space illegally today. People came to see Kentridge's masterpiece but the dirty Tiber and its abandoned riverfront left an uncertain impression. When tagging showed up on the frieze in April 2016 the city acted to have it removed. But the tagging elsewhere on the site remained, although AMA was ready to clean it if the city gave the go-ahead. When the annual 'Tevere Pulito' civic cleanup came around on Earth Day 2017 no one from Tevereterno or from the city government showed up.

\footnotetext{
${ }^{2}$ Povoledo, E. (2016), A Roman Legion of Volunteers Retakes the Tiber, The New York Times, April 26. Available at: https://www.nytimes.com/2016/04/27/world/europe/tiber-river-rome-cleanup.html
} 
Even Google recognizes Piazza Tevere as a place in its map database, located between Ponte Sisto and Ponte Giuseppe Mazzini. Thousands of people have made the pilgrimage to the site to see Kentridge's biggest art work. However, even after the huge international success of Triumphs and Laments, the city of Rome may not be ready to rethink its riverfront.

What could Piazza Tevere become with proper public investment, interventions, regulation and maintenance? 'Triumphs and Laments' made its potential clear as a public space. It fills a void in Rome's rich offerings. The city has a plethora of piazze but they are, for the most part, hard-scaped urban spaces with a dearth of green space, little public seating, and no real sanctuary from ubiquitous motor vehicles.

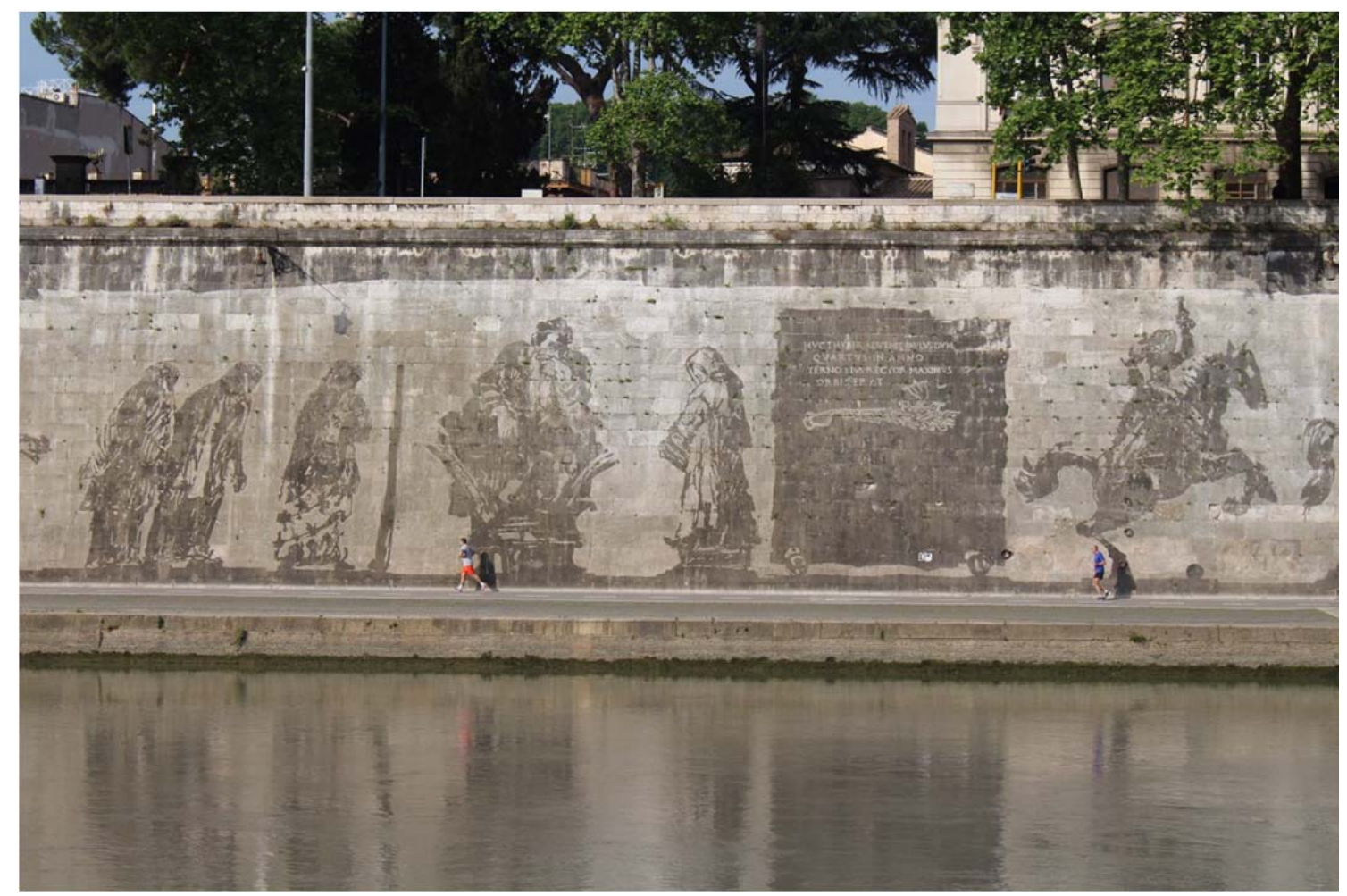

Figure 4. 'Triumphs and Laments' art work by William Kentridge in Rome, on the Tiber riverfront. Source: the author.

Piazza Tevere and the Tiber riverfront in general would provide an alternative public space for Rome, a linear green park where residents and guests could unwind from the intensity of urban life.

In lower Manhattan the transformation of the abandoned rail lines into the High Line brought about enormous change in the way that neighborhood is perceived and used. It also led to a huge increase in property value and tourist revenues. Similarly, Rome's forgotten infrastructure, its riverfront, could spawn an urban renaissance. The hard part has been done. Now is when - in a normal city - the administration would step in to provide the much needed upgrades and maintenance. Working with local associations, first and foremost with Tevereterno, it could fund competitions for public seating, lighting, and new ramps and elevators to make the site accessible. In place of the large- 
scale disorderly and banal tents which infest the riverfront each summer, a competition could be launched for limited-scale, high-quality, temporary constructions, more Venice Biennale than country fair. The administration would treasure Rome's resources, especially its abandoned infrastructure, and work to instill new vitality in the city's many forgotten places.

Good architecture is like editing; we take what has come down to us over the ages, and analyze it critically, evaluating what works and what doesn't work. We use the existing as our raw material, whether it be vertical facades, stratified landscape, perspectival views or consolidated culture and commerce. The challenge for designers in a rich and complex urban context (none more so than Rome) is not to compete and to stand out. Nor should our objective be to embalm the past under glass, as if history has ended. The early history of Piazza Tevere has shown that sometimes the most promising resources are right before our eyes, awaiting a fresh approach and a vision that artists serve to provide. The experience of 'Triumphs and Laments' teaches us that good ideas are very often met with opposition or indifference, but that with perseverance they can reach fruition. Like so many initiatives in Rome, the creation of public art on Piazza Tevere was possible despite all of the obstacles the public administration placed in its way. Imagine what could result from a collaborative process involving progressive leaders and a motivated, innovative and international private sector.

To cite this article:

Rankin, T. (20/8). Art as a catalyst to activate public space: the experience of 'Triumphs and Laments' in Rome. The Journal of Public Space, 3(3), I39-I48, DOI I0.3289I/jps.v3i3.II 37

This article has been reviewed and accepted for publication in The Journal of Public Space. 